\title{
Word and its Origin: The History and Evolution of Fjalëzës in Albanian
}

\section{Gladiola Durmishi (Elezi) (PhD.)}

\author{
Department of English Language and Literature \\ University of Vlora "Ismail Kamal", Albania \\ Email: gladiola.elezi @ yahoo.it
}

\section{Edlira Çerkezi (Duro) (PhD)}

\author{
Department of English Language and Literature \\ University of Vlora "Ismail Kamal", Albania \\ Email: edlira_cerk@yahoo.com
}

Doi:10.5901/jesr.2013.v3n7p388

\section{Abstract}

\begin{abstract}
The problem of nodes in the English language is one of the fundamental issues that 'the historical grammar and take into Consideration a node respectively. General fetures detection mini word a helpful collection of information at Linguistic sector that 'makes Possible the Recognition and analysis of this mini words from genesis to this day. Principal issues that Gives "identity" and assocation mini words a language Will Be the object and the point of reference of study.Aims achi a genuinely Linguistic Interpretation through historical genesis of the "Missal" Buzuku. Multifunctional dimension of mini word a wide range of its use as a Numeral, Such as joints, and even indefinite pronoun, behave through use contectual and concret. The examples of recent Attention Will Be paid to Linguistic Ability wordformation mini word a part and an object of study morfo sintax.Through a literature study distant decade have tried "dare" somehow to enter addressing nodes, there is a Tudy and Linguists own w eight, but Also Recognize English language qualification level.Necessaty studies and we w interpretations directly related nodes, Which Can Be Brough with arguments that 'further studies the pronlem of English nodes behore more clear.
\end{abstract}

Keywords: problem miniwords, a, language nodes

\section{Introduction}

Word $a$ is minimum unit formally, but it carries a historical genesis of the formation, there is a polarity of understanding and functioning. For genuinely linguistic treatment will be referred to as the scientific personalities: E. Çabej, Sh. Demiraj, S. Reese ES, E. Lika, K. Topalli., Who interpreted cast big ideas about the problem of joints. The problem of the joints has been one of the really controversial issues although there are historical grammar resources Albanian linguistic systems. Through dressed thought in scientific dimensions, these personalities have shed light on the serious character problems affecting the grammar of the English language. Augmenting character interpretation has thrown prof.Shaban Demiraj at article "The Problem of the joints of the Eagle", which is addressed the issue of front and rear joints. According to prof. Demiraj must take into account the specificity of Eagles nodes that have penetrated deeply into its morphological structure whom language. This issue have paid special attention to many linguists, Albanian and foreign, still do not have a common position not only to specific secondary issues, but also for the core of the problem. Beyond this, by prof.Demiraj will be handled node function of the front and the back node from the beginning of creation. Çabej in the article "About some questions of the history of the English language" has given an additional material, crowned so a language decent work and, being superposed affordable works linguists Selman Riza, Faith Bokshi Shaban Demiraj. This problem obviously requires reliability, precision, depth linguistic thought and strenuous efforts that were made by the scientific contributions of our linguists.

Various problems arising in the historical study of treatment of joints such as: what is the source, as they are formed, what functions they perform. Regarding to this important issue, not exempt the opinions of scholars' compilation of dictionaries, and Albania specialists Indo-Europeans. All these questions raised from the ordinary reader and to receive response linguists not rigid, dry, but with a background etymological based on linguistic examples argument, which is a type of certificate issues, will take into consideration. 
About basic issues of handling special problems of joints will be referred to a language-based analysis, interpretations and attitudes against word $a$.

\section{What does word a at Albanian language?}

Word a has a multifunctional use in Albanian. Finds use as a numeral, such as joints, as indefinite pronoun. Given Dictionary of Language ES 1980, word used within certain contexts with linguistic descriptors overtones adjectival function. Also finds use as word pattern, as numeral liner, as a basic numeral as conversational adverb, as joints joshquese, as pakufishmëri and a first numeral of all numbers.

\section{Diachronic linguistic interpretation of the historical genesis of word a}

Diachronic reading of numeral $a$ in Albanian language has long attracted the attention of historians whom her language. Numeral along with the class of pronouns, names of body parts, kinship attachments ... etc.. form a basis for diachronic linguistic comparison in the area of vocabulary. "* / Oinos / (: * / (H) O-no-s /) cf..: Gr. Oivn, lat.Attire phonetic <një>, formed in Albanian literary language, this numeral has darkened etymological connections with themes adjectival evidenced in different languages UNUS indoeuropiane (/ oinos /), ir. vj. oen got. ains "a".[1] This has resulted in diachronic interpretation of this numeral different linguists, Albanian studies and Indo-European, holding various positions. "Diachronic research of this numeral hindered some unresolved issues in the comparative internal, which are related to functional diversity and formal unit in the English language as well documented today in the dialects of the Albanian diasporas dialects " [2] . For example: this unit is used as appropriate to the function of numeral pronoun undefined node joshquese. It also comes in a number of forms that have the grammatical indicators. As the needs of first-hand, as etymological interpretation question the resolution of the following issues:

a. Definition of a unit source function, from which trickled other functions;

b. Reconstruction of a common platform English, from which are derived the other variants, as well as the reasons for their acquisition;

c. Establishing the relative and absolute chronology for the acquisition of phonological structure [nə] together with the corresponding function.

Diachronic into language review shows that an English language unit has functioned as genuine numeral. As such, it regularly went proklitik position within the cluster numeral + name (/ word named). Initial function and topic allow the variety of forms today dialect, separating a reduced vowel forms as representative form (paradialektore) unit under review. Reading further diachronic as well as basic shape reconstruction protoshqipe directly related etymological interpretation numeral a in Albanian. "Etymological so-far studies in the field of Albanian, followed methodological criteria to establish direct etymological ties to one of the topics that demonstrate the various Indo-European languages: * $/(\mathrm{H}) \mathrm{O}$ no /, * / (H) O- uo /* / (H) O-ko /* / SEM /* / sm /" [3] .

\section{Treatment at the semantic level of grammatical word a}

To talk about the use of the word, can not escape its setting as part of the lecture, because its lexicon-grammar evaluation has led to a wrong use may be consequences for the structure of the Eagle. "In our tradition a word grammar bashkëvajtje with a name is kept as a numeral and a knot undefined" [4] .Such an approach may be seen in the first edition of morphology and FGjSSh, 1980, which in this case has followed the morphology. In the second edition of a treatment morphology as undefined node is removed, i know what ur worth përemërore. It seems that the separation from previous treatment is not complete, because it is there stated: "In this use the word a meaning and function answers undefined node of those languages that are equipped with the knot. M. Celiku firmly held its treatment as knot joshquese, as he kept the handling of words: some few, as Node joshquese plural, treatment is long suppressed Albanian Grammatology. This thought he was trying to argue the article contribution for two problems of today's Albanian language morphology, has defended the papers "On several problematic issues of today's Albanian language morphology" and has applied to practice English language Grammar works [5] .

In the first article M. Steel creates a complex system knots present knots zero on one side, and endings knowledge on the other hand, which is not argued theoretically satisfactory and there is plenty of controversy, appearing in ot terminology used. He sees this possible link system nodes Eagles:

1. zero knot + singular name (son), 
2. node joshquese + singular name (a son),

3. the name singular + definite article (son), item

4. zero node + name amount (boys),

5. node joshquese + plural name (some / some boys)

6. the name of the amount + definite article (boys) item (SF, f.159).

Examples such as: "I have no daughter," the girl's name node zero, zero endings (SF, p. 159), while examples: "The teacher put his hand in his pocket" (SFG, p. 161); and "Here was held the event" (SF, p. 162), names: pocket and termination events shquese zero. Is not the place here to deal with this CE Issues. At this sense see two connectors: a) jack and b) a son.

M. Celiku claims that guy with zero knot, "a person (in the broadest sense spiritual) abstract thinking", while a boy's name, node, comes the idea of a person among people similar "idea According to him, provided by to node joshquese a flame joshquese the bending pashquar (in the given case is zero). This opposes grammatical meaning of meaning guy form the "node joshquese", which is incorrect, because, otherwise, we must recognize that guy in the link form (2) has no grammatical sense." In fact, the meaning of" node "an indelible as opposed to node zero, but comes in contradiction with vetorë pronouns it, this, so either these words should be kept as node shquese, or a word is not a knot" [6]. Son form, does not say which kind of counters: boy form, "form" a guy or two. It is not hard to understand that there's nothing we traverse knots endings, present a zero, but opposed nominative forms, and that this complex system of connections, endings knots, it helps to better understand who its contents easily category.

\section{Treatment of word a as a numeral in Albanian}

Regarding the phonological structure of the unit should be noted that in today's Albanian literature is a form generalized in all grammatical functions, among them the numeral: Examples: "What do himself a $r$ Kunda three!No, no; an anti four all Skënderi to. $\boldsymbol{A}$ window to the front, a trapeze and five chairs ... etc.. "[7].1. Meanings of pointer a as numeral:

a) In relation to a name that names numerical items, such as a limit generic sense (Traverse) name to mark a copy of a class of things. In this case used as a numeral, the meaning of which is clear in Traverse quantitative or note the amount: (How many apples in the basket church?) - Had a basket of apples.; But maintained even when there is no opposition: down, across the plateau, flew a falcon, who lost a black ball away from Nome (F.Ballanca).

b) In negative sentences numeral one is synonymous with the pronoun none can be replaced by him: During all night was thinking and didn't say a word.

c) Numeral a can win even at adjectival sense, entering into relationships synonymous with the family name / the same: Take a song, both men said the master of the house, - highland fielders of a blood have the same enemy press us ( S.Krasniqi).

d) Near names that do not have separate plural form, using numeral is necessary to update the number of the name, which without this will be interpreted as plural. Let us compare the name houses in these two phrases: Behind the hill was home, where home name has partial understanding of, and behind the hill had a home [8].

An English language unit followed proper numeral functional chronological line $\rightarrow$ indefinite pronoun $\rightarrow$ knot joshquese. Through this side of time, it being genuine numeral first, used sintaksorisht with a function përcaktori pavetëmjaftueshë $\mathrm{m}$, ie.I $\mathrm{n}$ any case, as the accompanying names or other parts of speech, krhs.: A man not two men. I $\mathrm{n}$ these piles of words she has always had a weak emphasis, what tumiret of Tosk form buzukjane a reduced vowel.

\section{Thoughts on this treatment reports about using word a numeral}

A diachronic interpretation difficulties conveys that explains numeral a thesis as a formative version of the database * I (H) O-no-/ [9] .Mention here Meyer's opinion, which accepts the approach previously made by Stier-ind. vj. anya-"other" and gr. "Evioi some" rebuilding for all three variants common formative language * / enios /, but without providing for additional explanations. Pederseni adds comparison with tissue. vj. anya-arm. ayn "he", rebuilding a basic form * / an-ios I formation Indo-European comparative scale * $\{$-ios $\}$.As we have seen, this group linguists tend mainly to clarify problems phonology character off. Reconstruction of a form basis * / vnio-/ motivates both as qiellzorizimin hundores * $\mathrm{n}$ / $\left(\rightarrow\right.$ Al. / N / _ $\left.{ }^{*} / \mathrm{i} /\right)$ as well as early coming initials of the unstressed vowel of the unit. Resolving this issue in favor of topic adjectival ${ }^{*} / \mathrm{h}_{2}$ en-/ enables the etymological explanation numeral an Albanian. "Within this framework, numeral a readily explained as a form of extended * /-io / (pp * /-ieh 2 - I) subject përemërore * / $\mathrm{h}_{2}$ en-I: a <protoshq. / AniV-I: $\mathrm{m} .{ }^{*}$ I 
$\mathrm{H}_{2}$ en-io-/ f. / H 2 en-ieh 2 - / "[10] .

\section{How is treated Albanian word a as node}

As known, the English language, like most languages i.e. equipped with the node, node joshquese created only for the same number of $\mathrm{s}$. Even this number of use of it has some limitations. But mentioned cases where the general name used generalized sense, node joshquese a commonly used not as concise names, subject headings and abstract, if these are not followed by percaktor. Use of node joshquese $a$ in this case has prevented known fact that names of this type, when used in the singular pashquar have a partial understanding (Power set) indefinitely. Therefore, when there is a need q they be accompanied by a pre-established determinant indefinite sense, then usually placed before the indefinite pronoun some or [11] .

Albanian today using this link with names generalized sense is much more limited than that of node shquese. And this is understandable, but keep in mind that node joshquese a phonetically both semantically has not cut off all ties with basic numeral source from which it is derived.

In Albanian node is obtained through the use of numeral a indefinite pronoun before a name general. For the form it does not differ from basic numeral, being presented with the same composition phoneme. But differs from it by the lack of emphasis. Only by emphasizing distinguish it from the indefinite pronoun when it is not followed by a name. But by understanding a distinguished node numeral one because it has a lexical meaning very pale, that amounts to a full çsematizim when used before a name with sense generalist.

Node a in Albanian today is used before any form of racist content name. But the language of s old author shows us that before a name (of any gender) in Rasa gender dative singular rrjedhore she used to tour with a distinct form, taking ending racist content, characteristic for male names first lakimit, should be extended by analogy way, as the name query where $j(t)$ (egX / 82). Here are some examples:

Buzuku: "I was afruo same generosity of qytets s father earth .... why was urdhënova same gruo s widow with fed ... led djerje atop same mountain ...Klau Exekia $\mathrm{n}$ same vai big ...And there $\mathrm{n} \mathrm{h}$ ditëtë kun advice same. ...Turned his flesh like a flesh same little boy d ... Who let nuke shkuom njaj the old word for the right to ... [12] ("Missal" f.149, 137, $155,115,65,153,65)$. 19).

Budi: Sod relate njaj long time a week or a muoi njaj another man; ... Another njaj t teen ... another njaj girl. (SC 6,

White: (palmarius) njaj pëllambe (f.82), (parilis the uguale) njaj mass (f.83), (pedalis :) njaj legs (p. 86), etc..

\section{Treatment in linguistics contemporary word a as node}

Group toe joints, as well as functions as grammatical features, show great interest for general linguistics. Suffice $t$ mention here the dual role that plays the front hub surnames smart type, where it not only serves as a composite element of the surname, but also plays a role similar to that of pins racist content, that plays both a role word pattern and shape forming. As can be seen, $\mathrm{n} h$ this case we are dealing with a grammatical tool sui generis [13] , who has no partner in any other language ie. It is true that the Romanian has created a tool grammatical similarity $\mathrm{m}$. But between Albanian and Romanian at this point there is a change. At Albanian "front knot" is an integral part of adjectives knotting, who form a separate group as opposed to group of adjectives panyjshëm. P. sh.: compare: good, smart and brave, loyal. Courses in Romanian there two groups of adjectives: structurally distinct among themselves through the presence, or lack of "node front. "I $\mathrm{n}$ the language every adjective can paranyjëzohet only if the decision after a distinguished name. Elsewhere, the same adjective used paranyjëzuar [14] .P. sh.: compare: un om bun "a good man", omul cel bun "good man".

The same remark applies to "the front node" gown s gender. At Albanian language that has become part integrante gjinores, [15] and in Romanian this gown paranyjëzohet only if there comes pandërmjetshëm after prominent surname. P. sh. th compared o carte a elevului "a book of students" and cartea elevului "student book."

Between front joints of Albanian and Romanian there are other important changes in morphological and syntactic character. As front nodes of adjectives and gender race Albanian formally leave the same and their use is not restricted by syntactic certain circumstances, in Romanian "front hub" of adjectives is formally different and used in different syntactic conditions by those "node front" gender race (see the examples of the above r). In that language, as it is known, "the front hub" of adjectives, called "article demonstrative (adjectival)" [16] , del cel format (nj.), cei (eg) for masculine and CEA (nj.) cele (eg) for women, these forms related to those demonstrative pronouns ACEL, acei, acea, ACEL [17] . And 
front node of gjinores, called "article possessive (gjenitival)", comes with format al (nj.), he (eg) for masculine and a (nj.), ale (eg) gender female of natural. Obviously, $k$ hese nodal forms have a different source from node the front of adjectives. [18] Also keep in mind that as the front hub of adjectives as well as that of gender race, being used only in certain syntactic conditions are not transformed into pamungueshme then integrate, adjectives, namely gender race, as they are made in the English language. As a result, the front hub of adjectives in Romanian plays a dual grammatical role word pattern and shape pattern, just like in English.

\section{Thoughts on this treatment reports about using word $a$ as node}

With all the differences between the front nodes and gjinores adjectives in Albanian and in Romanian, the fact that in these two languages in addition to back shquese joints are acquired these front hub is a linguistic phenomenon that catches the eye and therefore has fair attracted the attention of a number of researchers. K ETU has a range of difficult issues that have not yet been fully clarified, such as the ratio between the chronological back joints and toe joints, the origin function of the joints of the front and is there any historical connection between Albanian and Romanian in the development of a nodal system such similarity. This issues, are related between them, so that their explanation can not be done only by examining together. But, automatically understood that a work such presents a number of difficulties partly unbiased up today. Therefore, here will stop at the beginning in some more or less general considerations.

First, keep in mind that it is impossible to explain to the chronological relationship between the back and front joints without first explained the origin of the latter function. In the case that those in English and in Romanian did not have sometimes seconding function, which is the origin node function in all languages equipped with a nodal system, then the issue is resolved respectively chronological report. And $t h$ does not really like to think that back nodes that play a setter, get out of the front nodes, if these have not ever had such a feature.

Such a function node can not perform except in the class names, because only names could be developed to oppose certain sense undefined sense. Also, given that even name node (shquese) $n h$ very beginning can not be displayed in a gown, such as gender, which ie languages served (and serving) express përcaktorin. "As a result, it is implausible as Graurit opinion RRL 1, 1967, 16 Romanian and Albanian node in beginning have been paranyjëzuar". [19]

\section{Using word a as indefinite pronoun}

Nonuse or use of the indefinite pronoun before an impersonal name it according to certain rules that must be followed exactly known, if we want to think of writing slip. Pashquar name from pronoun a prihet not in these cases:

1. "Where is the extender of the verb am and generic sense. Coherency of the object q expresses the subject and the object that said kallëzuesori, connection type genre: apple trees; Man is a being with reason; or object type: Sun is the planet; This is home; This is a book; This is this pen is a pen. In these cases the use of the pronoun would narrow generic sense dh name coherency genre or type item type would break, which would be unacceptable in this context " [20] .

Examples: "The dream that told him her husband was not already a dream (Gazette Century date. May 10, 2000); Losing elections is not a tragedy (VAT); You're a professional (film); Loss of support, there is a reality, as some see it (Gazette Century, 13 May 2000) a; This man can not be a beggar (S.Godo, Sk ënderbeu, 236), "are not in accordance with the regular rate would be without a. For example: Was it not, indeed, this good news? (press), it seems that ërdorimi $p$ is justified in order to avoid the interpretation determinant note name. In fact, even here it is not necessary, but avoiding a will require pronoun setting this in another country, apart from the name: This is not really good news?or $A$ is not really good news this?

2. When is the extender of some other verbs and functions as a determinant kallëzuesor kryefjalës or kundrinorit: "When he grew up, he became a good guy; eldest son became a teacher; remained good man" etc.; Examples: " If they do not I am a groom, I would like to remain a man Gega said, "(Z.Ç ela snow Bulletin, p.225); "This mospërkim hours can constitute himself a conflict?"(Ce decolage horaire Serai-il a lui seul un conflit?) " $\{0\} ;\{10\}\{0\} \quad\{10\}$ Kadare, "Ra this mort eu saw", p.183); gym teacher says that, with the stature that I can become a good basketball player, (T.Lac 0, "A Night with the sh", p.17); I do not know any other language that its first phrase have a baptismal formula, (I.Kadare, "Call in the studio", p.277); Athosi is a long time considered a holy place (the press), the use of one is not in line with the norm, is the impact of other languages should be avoided.

3. When used in incomplete sentences, with function kallëzuesori (the so-called nominal sentences), eg: "Around 
any suspicious noise. Night.Silence. ( $\{0\} ;\{/ 0\}\{0\} \quad\{/ 0\}$ Kadare, South City, 77) afternoon.Tanush Martini sat in the same place and smoked tobacco (S.Drini, Martini Tanush, 102). "Uses such an impact or translations from Western languages, that are not in accordance with the norm: "One morning all (VAT, the title of a show); $\boldsymbol{A}$ general realization Albanian Television (VAT); (Anywhere from right were gathering people). - $\boldsymbol{A}$ quarrel, said astronomer (I.Kadare, "Castle", 44); $\boldsymbol{A}$ holy mountain monasteries "(print).

4. Do not use a pronoun before a meaningful name in the generic function of an isolated ndajshtimi. Use of pronoun a example: the problem is how to connect around the world with the words of this language, which can called world fjalësimit process, a term that we have already used in the sense ... (text) is not regular.

5. For the same reason had not a pronoun used in the following examples, where the name of pashquar works as fair kundrinor or kundrinor preposition: "No man who was carrying a gun, would not escape the army (S.Godo Skanderbeg, 228); "Right now their position is unfavorable for an attack" (I.Kadare, "Castle", 149). " $\mathrm{N}$ both names phrases: assault weapon, generic sense, which can not be realized in this context in the presence of a word.

6. When used as a synonym of pronoun each, a pronoun is not common in the English language, especially spoken language. It is natural, when the name is followed by a subordinate clause qualifiers, but does not seem pëlqyeshë $m$ and strongly regular when no extender name. Use of name in outstanding form with generic meaning is in these cases more regular [21] : "Stood in front of a gate and press the alarm button ...)I fell in mind that an alarm can be terminated and the best was knocking ... (T. Laco, "One night the rain", 3); $\mathrm{He}$, a little later, said murimi a man really weakens a wall (I.Kadare, "bridge with three arches"); Seven years are not a little to test a man (Dh.Shuteriqi); Some say that it was about finding water, but as they themselves were not able to explain what fellowship can have a hidden vent fence deep under ground water (I.Kadare, "Castle", 154) ".Using such a construction, development seems to be influenced by foreign languages, but sometimes these can be justified, as in the example above, the need to avoid ambiguity: fence outstanding forms and water forms can be understood even as uses anaphoric.

7. In other cases, when the phrase is characterized by suspicion mode that assumption, the use of any use in a country will be more acceptable, as it seems clear in the following examples: "In this way must surely have a hotel "(N.Lera, "The night of the premiere", 4); "would give the invitation ..?.But whether it was true or invitation was a toy, behind which hide a trap? "Mr. Ç ela,"Bulletin of snow", 233).

8. pashquar name cuts by a pronoun, when characterized by a pronounced qualitative trait and is followed by a subordinate sentence descriptors, which contains a situation is a consequence of this feature and expresses its high level, amplifies it.

Building a pronoun expressed in this sub-species and a certain sense, for example: "There was a strong eye to kill tration with a view" (M.Kuteli); "It was a steep city had broken all laws of architecture" (I.Kadare). Feature name can be given by a përcaktori, usually qualitative adjective, eg: "It was not really snow;" It was a light rainfall that soils have absorbed quickly "(Mr.Ç ela, "Bulletin of snow"); "It was a rock teeth that strike fear" (T.LACO). But the trait can be given with the lexical meaning of the name, usually figurative sense: "It was a fox not had friend"; or in other cases, it is the subordinate sentence descriptors, which makes clear the feature and scale of him: "He was a man who had compassion" (V.Koreshi, "Balada of Kurbin", p. 24); "On Sunday, to walk late at night to zallishtja the wilderness, I felt a consumption that I had never experienced" (I. Kadare); "She was a young girl, thin and weak, but with a charm that getting dizzy "(V.Koreshi); "Fate had called him to lead such an army which I had friend in the world" (S.Godo, "Skanderbeg").

Often subordinate sentence descriptors may not be present, but it is implied by the context or discourse situation: "It was a scary dance and monotonous" (I.Kadare, "Castle", p.43); "Rina was a very pretty girl.K Ete felt it itself "(V.Koreshi, "Balada of Kurbin", p.239). I n all these cases, a pronoun reinforces the idea of sub-species, has the function of certain sense, characterized as popular spoken language, literary language, and is the standard language norm.

\section{Thoughts on this treatment reports about the use of word an as indefinite pronoun}

In connection with the report chronologically between the functions $\sim$ numeral indefinite pronoun, English language data and Indo-European lead to acceptance of the earliest appearance of a unit numeral function. Indefinite function of pronoun is the result of using numeral one with a sense (general) indefinite, where the idea of quantity passes into the background [22]. In this case, it should be noted that the use of a unit as indefinite pronoun belongs to later periods of various Indo-European languages and is not related to Indo-European pronoun bases (demonstrative reflexive), from which is derived the numeral in these language [23]. 
About phonological structure of this unit, it should be noted that in today's eagle is generalized forms a grammatical function as indefinite pronoun, eg: "I met with one of which I had ever seen. It's one of mine ... "and so on.

Unit faces as members of particular sentences, so when it is used as indefinite pronoun: a coming of a heading: or as numeral named, with the value of the entire cluster numeral + name: cf.. Came one (man) and not two. In this syntactic function she carried necessarily focus on them. At this situation would be quite normal in Tosk dialect, it can not be preserved as such in Geg dialect, phonological system which vowel / ə / pronounced missing. In this way a final explanation gege a secondary variant, analogical appear

fully stars. Conversion of analogical dialectal / ńə / $\rightarrow$ g. Couple must have started before the century.XVI (Buzuku). Budi his face er trace the earliest linguistic situation Geg dialect, where a unit in this idiom yet retain phonological structure / ńə / when used as a main limb in the sentence.

\section{Intangibility in other languages and in Albanian language}

Receiving word a node undefined a joshëuese or acceptance of node zero is, no doubt, influence of west language grammar. In these languages the meaning of uncertainty Words placed before the name, which are necessary to show a degree of uncertainty item by name. These words, called node, object node non defined and defining node. Each of the this language has its features using nodes, for example: English has not knot non defined to plural and, in certain cases, even non defined node of the singular is used, while in French, which also non defined knot plural, only in exceptional cases can not used non defined node. For some of these special cases can not used non defined node. For some of these cases, in those languages it comes to zero kanot.

$\mathrm{N}$ English language situation is different. In this language name has two synthetic forms, which oppose indefinite form (there is no specific marker, therefore endings joshquese zero node are meaningless) and prescribed form (which has a special marker, which in some racist content forms are merged with suffixes racist content).

This two forms realize the meaning of undefined terms of designated. Understanding the non defined displayed as generic sense, which means more opposition (when we say: Swimming is taught in the water, implicit opposition not to the ground), as partial sense when said mass or unspecified quantity: rain; Collect olives. Defined meaning emerges as individualization: trgim of an object defined in different ways (anaphoric, cataphoric a situative), or as a generic sense, when classes denominated items is known or given discourse situation as such. Implementation of generic meaning $\mathrm{t} \mathrm{h}$ an unspecified name and a defined name can be clearly seen in the use of rrjedhores gjinores a name as a determinant of a different name: olive oil oil Olive.

Autonomous use (with or without preposition) undetermined name in Albanian can achieve or generic sense, or partial understanding, but led by defining words (numerals or pronouns) carries only the generic sense, but, of course, without opposition, because it neutralized the defining words.

\section{Albanian features compared to other languages: English, French, Italian ... etc..}

Despite the similarity that category determination in different languages, can not be the same as the use of tools that mark the internal logic that characterizes any language.

a) In French, for example: partial understanding expressed du partial nodes (<de + le), de la, des (<de + les), which are formed by the preposition de (which has lost its meaning as the preposition in this use) and by defining node, whereas in English is expressed in the form of unspecified name: Je bois du vin ou de la Bier."Drink wine or beer." In French the name preposition expressing local circumstances, turns out to be associated with the specified node, while Albanian indefinite form: Je vais à la maison."Go home."

Indefinite pronoun a Eagles and undefined node of the French, who comes also from numeral, is also the hub of English that no about ancestry with numeral, are similar in their uses but not ike idea. Albanian pronoun like to use with the knot of these languages, when it expresses the meaning of vetëmsisë, but not used in the English language, the name of pashquar express gender (sex-type connection). Such translations found in bilingual dictionaries FrenchEnglish, Italian-English, English-slip etc.., Finds in fiction translations from these languages, but especially in the daily press and in methods for teaching these languages States. Dog of these languages taught in our schools and in different courses, understand how much damage done Albanian language. I give my few cases with relevant examples of a method of English and an Italian-English dictionary:

a) Constructions and idiomatic expressions

This is a room. This is a room. 
That's a wall. It is a wall.

That's a window.

A no is a window.

This is a lamp. This is a lamp.

This is a pen. This is a pen.

And this is a pencil and this is a pencil.

This is a book. This is a box.

(D. Hick, English for all, Tirana, 1993, p.[23]

b) Uno as knot joshquese, (masch. femme.): 1) un quaderno-a notebook; una mela measured-a baked apple ....; ha avuto una Paura had a fear (F.Alexander Z. Simon, Dictionary Italian-Albanian, Tirana, 1988).In all these cases the use of a word in the translation is wrong, the meaning is not clear, nor precise, if we consider the linguistic contextual explanation above.

\section{Functions syntax of word a as node}

When accompanied by a node, the name used in the form of pashquar: As soon as he had opened a mënjollë little toward the sun; After a few days a Rustic set up a songs; Lead ciflosi a stone in the wall of a house. When the name of a node is defined by an inclined possessive, can be used in the form of distinguished and pashquarën.

1. Name used in outstanding form, when determined by a possessive pronoun: "My friend, your brother.", Eg: Then came a letter from a friend of mine; From our man found out that kryekapedani us love with a shot somewhat arnautkë; There he met a friend of his.

2. The name used in the form of pashquar when pronori used emërzuar: a friend of mine, a friend of ours, your brother, a saji man, a girl of his own., Eg:

"A machinegun ours i stopped advancing Nazis; There was one of our batteries; your church under the pillow of the hotel an English newspaper that contained a poem of mine; Our Party has today a thought sajin, clear, well defined, on all major issues, domestic and foreign; Skënderbeu like to see among them a man of his own; Just in this novel have internal enemies physiognomy of their own " [24]. Functions of morph - syntax of word a According to tradition grammatical English, nodes are distinguished as separate parts of speech. "In this class are usually involved nodes back a shquese and called the front nodes, and in some grammar node pashquar domed a " [25]. Against such treatment may be asked a series of remarks like:

i. Including of the so-called front hub in a class with the back nodes can only be justified by relying on historical consideration, viz. the fact that, historically, they have a common source, which stands out in the formal similarities between them. But draft-that they are different functions altogether. While back nodes play primarily a role shques a individualizues., The so-called front hub, perform very different functions, which generally ot not comply with the function of the joints. In most cases (eg: surnames nyjshëm), they play a similar role to that of a morpheme. Of a particular type, that performs both function word pattern and shape forming.

ii. Back nodes or shquese, dogs that are prapangjitur long name, lost their independence as separate words and are transformed into morpheme word pattern category shquarsisë.

iii. Front nodes, when playing the role of a morpheme of a particular type, not autonomy as separate words, they do not exist in isolation from the word where they belong.K ështu example, the front hub surnames nodes type paranyjëzuar names: Monday, hard-pressed, speak-it etc.., Or some pronouns such as: such, his, who etc. ., is an integral part of the word, and not separate words. As for less can be taken as separate parts of speech hub on the front of the race equality. "Regarding word accepted as pashquar domed knot, it basically is an indefinite pronoun is used before a name pashquar" [26] .

The form of a word in the broadest sense of the term is not only conditioned by morphological circumstances, but there are also links to a large extent with conditions morph syntaxes. "I n accordance with this principle, there are words that so methodically right must be viewed in a non-isolated in itself, but in ngërthim sentence. Syntactic Phonetics of Albanian Geg tells us. A, which does not prevail in the old literature of the north, so it is a relatively new form has emerged in paratheksor position, or at proklizë, in composites, such as: twenty, a hundred or sandhi, according to a phonetic rule holds especially in this dialect. "[27] .

"Slate indirect pointer, which is characteristic of the male names first bending, which is attached form Petrous / couple.As such he can not rrjedhohet pandërmjetshëm of racist content eptimit indicators përemëror indoeuropian: cf.. lat.(E.) Unus, (Gj.) Unus, (dh.) uni. In endings racist content $\{i / j\}$ of the unit Demiraj explains the action analogical class 
male names first bending, as happened interrogative pronoun whom (: where jt).A similar effect appears to be obtained even with surname function perremëror (i) the same (: j-), (Buzuku) (i) njaj (: couple j) "only; the same" and forms buzukjane the pronoun that: () sejtë (: j), $n$ total of "[28] .

"As stated above, the grammar rejects grammatical English tradition, not accepting node joshquese a separate part lecture $s$. This state is held, obviously contradicts what has been achieved in our grammatical tradition. Now known that node joshquese basic numeral source. The numeral on the other hand has gone indirectly knot, but through its use as an adjective undefined " [29]. To fully prove that the node can be treated and reviewed in function of part lecture, apply more advanced studies in linguistic level, specifically in it morfo-syntactic, grammatical system approach of other European languages.

\section{Results}

Using a language worthy material in different vocabularies examples entirety Eagles meet extensively with multifunctionality and semantic value word carries. In this short paper modest, Aiming to bring clearly aspects of the chronology of the birth, evolution and development numeral a linguistic unit. Decades of the twentieth century scholars both domestic and foreign, have sufficiently addressed issues related to the development of this unit in the course of comprehensive studies of various parts of speech. These authors have treated word a different point of views. The treatment of the subject corresponds to undergoing word a change in the structure of the sentence in the English language. We presenting word a numeral one time, how adjective non defined and knots joshquese. Word characterized by variability. This type of variability it appears depending on its position in the sentence, and depending on the role it plays in the sentence context. In this perspective, we can say that:

Images before the form and number, written in the stone age, numerals are understood as one of the properties of objects. This unit, the first born is abstract mathematical needs further use of function as a linguistic unit, explaining thus en language links with other sciences.

Its use among older authors Eagles (Buzuku, Budi, Bogdani Matrënga), reflects again the fact that phonological evolution here has not deviated historical laws development Albanian linguistic system.Joining with the opinion of many prominent linguists, we can say that his abstraction in use following line: numeral indefinite pronoun - knot joshquese, where the latter seems to be more recent.

Fellowship and appeared particularly interesting use of this unit bashkëvaitje with the aforementioned units. Distinguishes here the phenomenon of emërzimit numeral. Also, as a word that shows the amount as opposed to other numeral, he gains the sense of an indefinite pronoun used as adjective, etc.For this word have recognized its ability word pattern and its syntactic functions. Given all of this material and linguistic basis of analyzed in detail word a question: Should treated word a category nodes context lexicon-grammar? We can say that this topic is treated extensively by Sh.Demiraj. Can not give a definitive answer, because it is a broad topic and widely as linguists weight remains to restore, reconceived reconsideration. Remains to be made more detailed studies and comparative approach, then by analogy with other European languages. In particular, the more complete will be when we bring analyzes the function specification of sintagmës head of this word structural syntactic constructions.In conclusion, we can say, that the specificity of linguistic diversity in the use of this unit seems to be special, unique and with a special contribution in the use of grammatical structure function of Eagles.

\section{References}

[1] B.Demiraj, "English Language counting system", Tirana, 1997, p.17

[2] B.Demiraj, "English Language counting system", Tirana, 1997, p.17.

[3] Ibid. F.17.

[4] Ibid, f.26.

[5] M.What eliku, M.Karapinjalli, R. String, "Practical Grammar of the English Language", Tirana, 1999.

[6] M.Totoni Our Language 1-2/2000, "About the use of the word" f.61.

[7] B.Demiraj, "counting system ..." Acts. cit, p.19.

[8] M.Totoni, language Our, 1-2/2000 ..., art. cit., p.63-64.

[9] B.Demiraj, "counting system ..." Acts. cit., f.27-28.

[10] B.Demiraj, "counting system ..." Acts cit, p.29.

[11] But when considering names are followed by a determinant, then a node is quite possible, as it is quite possible its use before a name generalized sense.Eg I bought a cheese (flour, butter, etc.) very well.It is a good man etc..Using node in compound words such makes it possible that in this case created a contradiction between a part of the object (or class) characterized by a given 
quality and the rest of the same thing (ie the same class), which is not characterized by this quality.

[12] As can be seen, in this case Buzuku used form - $a$-, as opposed to the ordinary - $h$-.Form - $a$-, in this capacity he has used in other cases (for example: on p. 265), but this form he uses regularly in function përemëror, such as: buying a piece dhō n njai qi ban urcoj. (p.209).

[13] Sh.Demiraj, Historical Grammar of the Albanian language, "The problem of the joints of the Eagle", Tirana, 1985, p.306.

[14] Regarding Numeral rreshtorë, these, with the exception of rreshtorit intiiul "first" regularly used "front knot" al he, ale, that is even before the race equality.Therefore "the front hub" rreshtorëve in Romanian, as in English, has become part of their integrante and plays a dual role, fjalëformues and trajtëformues along fundores-lea for masculine and-a for women (see: GLR I, 196).

[15] Regarding compound words wheat bread type, where the second limb plays a defining characteristic of gender Rasen, sh. remarks ... System, p. V 28.; Sh. edheV / 16-21 work present.

[16] Sh.GLR $107 \mathrm{v}$.

[17] Sh.ILR II, 235 v.

[18] Sh. for these Coteanu, Morfologia numelui in protoromana, 125vv.

[19] That this opinion was expressed first linguist, "Romania" LV, 476v., Speaking for the Scandinavian languages.

[20] M.Totoni Our Language, 1-2 / 2000 ..., art. cit., p.67 - 68.

[21] M.Totoni Our Language, 1-2 / 2000, "About the use of the word" f.69.

[22] Sh.Demiraj, "Grammar ...." 525. Other Indo-European languages sh. Sommer handb. Lat. 440.; MAYRHOFER EVA 262v.

[23] As indefinite pronouns indoevropian source proved threads përemërore starting with a tektal labiovelar: * / k /, * / k/, * k $0 / \mathrm{k} /$, which used as interrogative pronouns subjunctive; sh.Brugmann Grundrib II / 2; Szemerenyi Einführung 220V.

[24] A.Kostallari, E. Lafe, M. Totoni, N. Cikuli, "Albanian literary language for all", Tirana, 1976, p.159.

[25] Instit. of languages. and Let., "Phonetics and grammar of the language of literature today", Tirana, 1976, p.15 - 16.

[26] Instit. of languages. and Let., "Grammar of the English Language", Tirana, 1995, p.38.

[27] E.Çabej, "etymological studies in the field of Eagle 1", Tirana, 1995, p.95.51

[28] E.Çabej, "etymological studies ..." Acts. cit., p.95.

[29] G.Elezi, "Eagles interpretations linguistic investigation is 1" Skopje, 2012, p.22-23. 